\title{
ANALYSIS OF CORRELATION BETWEEN STRESSES AND FATIGUE LIVES OF WELDED STEEL SPECIMENS BASED ON REAL THREE-DIMENSIONAL WELD GEOMETRY
}

\author{
Przemysław STASIUK*, Aleksander KAROLCZUK**, Wiesław KUCZKO*** \\ ${ }^{*}$ Formopex Sp. z 0.o., ul. Braci Prankel 1, 47-100 Strzelce Opolskie, Poland \\ ${ }^{* *}$ Faculty of Mechanical Engineering, Department of Mechanics and Machine Design, \\ Opole University of Technology, ul. Prószkowska 76, 45-758 Opole, Poland \\ ${ }^{* * *}$ Chair of Management and Production Engineering, Department of Mechanical Engineering and Management, \\ Poznan University of Technology, PI. M. Skłodowskiej-Curie 5, 60-965 Poznań, Poland \\ przemyslaw.stasiuk@formopex.pl, a.karolczuk@po.opole.pl, wieslaw.kuczko@put.poznan.pl
}

received 4 May 2015, revised 11 December 2015, accepted 22 December 2015

\begin{abstract}
Welded joints are areas of increased stresses in construction. The reason for this phenomenon is associated with the nonhomogeneous mechanical, structural and geometrical properties of the weld. In the article the correlations between locally raised stresses due to real geometry and fatigue lives of non-load carrying cruciform joints made from S355J2+N steel are analysed. Stresses were computed using Finite Element Method (FEM) based on real three-dimensional weld geometry obtained by 3D scanning. The specimens were experimentally tested under cyclic push-pull loading with a zero mean value of applied force. The correlation was analysed using Pearson's correlation coefficient and statistical hypotheses. It was shown that statistically significant correlation exists between maximum values of normal stresses and fatigue lives.
\end{abstract}

Keywords: 3D Topography of Weld Joint, Non-Load Carrying Cruciform Joints, FEM Analysis, Correlation Analysis

\section{INTRODUCTION}

Welding is a very popular method of joining steel elements. There are many possibilities to automate this process through the use of specialized equipment. It is not complicated in the case of long, straight welds but for small parts, where access could be problematic, automation could be expensive or sometimes impossible. Therefore, manual welding still remains an important element of technological processes. The shape of the manually welded seam is characterized, e.g. by varying the values of the angle of the face and the radius at the weld toe and also by existence of ripples. The welding operation causes residual stresses, changes in the structure of the material, forming a structural notch and also a geometry notch studied in (Nykänen et al., 2007; Barsoum et al., 2011; Blacha et al., 2011, 2013). The influence of these defects can be reduced by heat treatment (the heterogeneity of structure and residual stresses) and by machining (geometric notch) (Kirkhope et al., 1999; Ting et al. 2009). However, this type of treatment carries a considerable financial outlay. Popularity of welding makes attempts to find methods to better understanding the changes occurring in the material and the effect on the fatigue strength.

Analysis of a shape of the weld was taken into account by many researchers. In the works of (Williams et al., 1970) analysis of the influence of a welding geometry on the fatigue behavior of transverse butt welded joints in ASTM A36 steel and A441 (high-strength low-alloy structural manganese vanadium steel) was conducted. The analysis has shown that the height of the crown of the weld better correlates with fatigue lives than radius at the toe of the weld. Along with the development of measuring method and equipment availability, geometry mapping was getting closer to real weld geometry. Measuring of a silicon mold of specimen were used to analyze non-load-carrying fillet welded cruciform joints in mild carbon SM490 steel (Lee et al., 2009). The analysis showed that fatigue lives increases with increasing the weld flank angle and the weld toe radius. Alam et al., (2010) analyzed the influence of surface geometry and topography on the fatigue cracking behavior of laser hybrid welded eccentric fillet joints (stainless steel SS2333). They have shown that the toe radius does not always dominate fatigue performance and the ripples can become more crucial.

$3 \mathrm{D}$ scanning is the most accurate method to obtain weld seam geometry. This method gives a possibility to create real model of a weld joint. The method was used to calculate stress distribution by finite element method (FEM) in cross welded joints in highstrength low-alloy ASTM A572 steel (Hou, 2007) and in overlap and T-joint in S355MC construction steel (Kaffenberger et al., 2012). It was shown in (Hou, 2007) that not all crack started from the highest stress concentration points. Kaffenberger et al. (2012) successfully applied mean value of toe radius determined as $0.2 \mathrm{~mm}$ to correlate fatigue lives with calculated stress amplitudes.

This present paper aims to analyze correlation between experimentally observed fatigue lives and different types of stresses being the result of imperfect weld joint geometry. The analyzed stresses are: nominal stress amplitudes, maximum local values of normal stress amplitudes, maximum local values of superposed 
normal stress amplitudes and mean values, averaged normal stresses (highly stressed volume approach). The analysis was performed on a non-load carrying cruciform joints made from S355J2+N steel. The shape of a weld was received by 3D scanning, as it was mentioned, this method allows to create a virtual model of a specimen and use it to calculate a stress distribution by FEM.

\section{PREPARATION OF THE SPECIMENS}

The welded plates were made from $6 \mathrm{~mm}$ thick metal $(\mathrm{S} 355 \mathrm{~J} 2+\mathrm{N})$ sheets with the base plate dimensions $200 \times 1000 \mathrm{~mm}$ and rib dimensions $30 \times 1000$. Plasma cutting was used to prepare elements. Parts were blasted after cutting. Edges of the plates were grinded in order to create correct joint. Welding was conducted by MAG method, with $1.2 \mathrm{~mm}$ wire, in $\operatorname{Ar}(92 \%)$ and $\mathrm{CO} 2$ $(8 \%)$ gas shield, without using clamps. Deformation of plates (deviation from flatness of main plate) after cooling reached $0.35 \mathrm{~mm}$. The specimens were obtained from four welded plates (marked as numbers 1-4) with geometry presented in Fig. 1 by saw cutting. The specimens from one of plate (number 2) were subjected to the heat treatment (stress relief annealing).

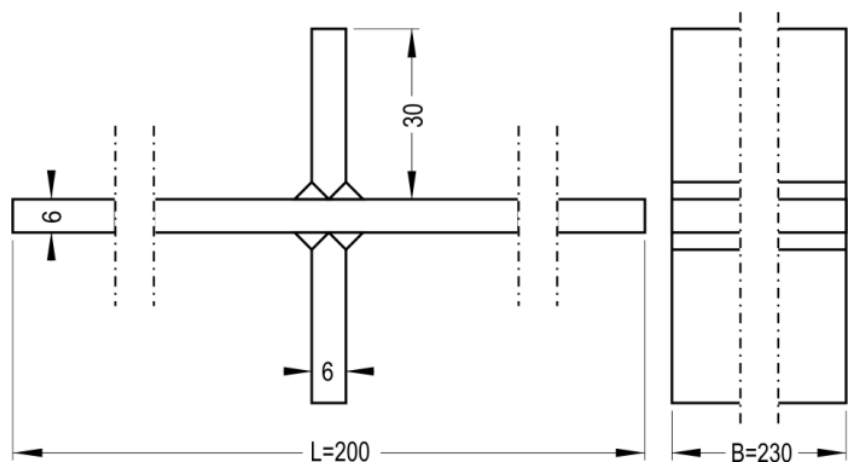

Fig. 1. Geometry of the welded plates

\subsection{D scanning}

The plates were scanned by using GOM ATOS device which applies refraction of white light bands on the element. Five scans for both sides of each plate were taken. The clouds of points were converted into a mesh of triangles and next into stereolithography ( ${ }^{*}$.stl). This allowed to mapping of the sample with $0.02 \mathrm{~mm}$ (distance between the points). Fig. 2 shows a comparison between measured points and output model.

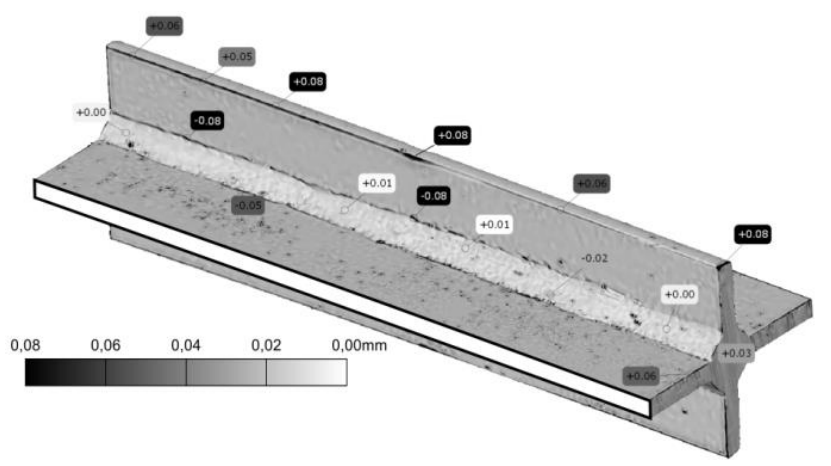

Fig. 2. Mapping of accuracy

\section{EXPERIMENTAL TESTS}

After scanning, the specimens for fatigue tests were prepared by saw cutting and milling. Thirteen specimens with $B=24 \mathrm{~mm}$ width were received from plate (Fig. 1). The specimens were marked as "no1.no2", where no1 is a based plate (1-4), and no2 is a specimen number (1-9). The specimens were experimentally tested under cyclic push-pull loading with controlled nominal stress amplitude $\sigma_{a n}(153.1 \pm 5.9 \mathrm{MPa})$. Tests were conducted until complete rapture of the specimens. Fatigue lives $N_{\text {exp }}$ were summarized in Tab. 1.

Tab. 1. Results of experimental cyclic push-pull loading

\begin{tabular}{|c|c|c|}
\hline Specimen & $\boldsymbol{\sigma}_{\boldsymbol{a n}}, \mathbf{M P a}$ & $\boldsymbol{N}_{\text {exp }}$, cycles \\
\hline 1.1 & 154.7 & 191890 \\
\hline 1.2 & 159.1 & 219650 \\
\hline 1.4 & 153.5 & 230470 \\
\hline 1.5 & 156.5 & 177650 \\
\hline 2.3 & 154.7 & 104480 \\
\hline 2.5 & 149.5 & 165980 \\
\hline 2.6 & 151.6 & 76150 \\
\hline 2.7 & 151.2 & 112710 \\
\hline 2.8 & 152.8 & 109600 \\
\hline 2.9 & 150.4 & 103040 \\
\hline 4.1 & 156.9 & 174960 \\
\hline 4.5 & 158.9 & 97680 \\
\hline 4.8 & 141.2 & 114290 \\
\hline
\end{tabular}

The stress relief annealing did not change significantly the fatigue lives of specimens. The reason could be seen in small width of specimens obtained by saw cutting or/and due to stress relaxation occurring under loading (Barsoum and Gustafsson, 2009). As result all data will be treated as one set. Fig. 3 presents an example of fatigue fracture surface.

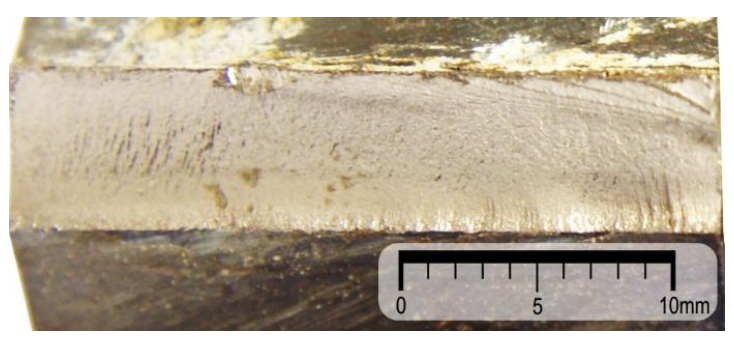

Fig. 3. Fatigue fracture

\section{FEM ANALYSIS}

The scanned models were converted into step file and imported into Solid Edge program in order to divide and prepare $24 \mathrm{~mm}$ width specimen models. Preliminary analysis was conducted to determine the appropriate mesh size. Finally, the maximum length of finite element equal to $0.05 \mathrm{~mm}$ in the welding toe was chosen. Fig. 4 presented mesh density used in FEM model.

Applied constrains and loads imitate fixing and testing in the fatigue machine with hydraulic grips under cyclic push-pul loading. Analysis were conducted in steps. At first (i) closing of thegrips were modeled. Straightening of a specimen associated with the 
welding deformation was taking into account and stress tensor components were computed $\sigma_{i j}^{(i)}(x, y, z)$. In next step the models were subjected to tensile nominal stresses oan reported in Tab. 1 and stress tensor components $\sigma_{i j}^{(i i)}(x, y, z)$ were determined. Static analysis was performed using a linear-elastic model of the body ( $\mathrm{E}=205 \mathrm{GPa}, v=0.3$ ). In Fig. 5 example (specimen 2.7) of maximum principal stress distribution is showed computed as superposition of steps (i) and (ii). The Fig. 5 clearly shows that stresses are highly concentrated in fusion line where all fatigue cracks were observed.

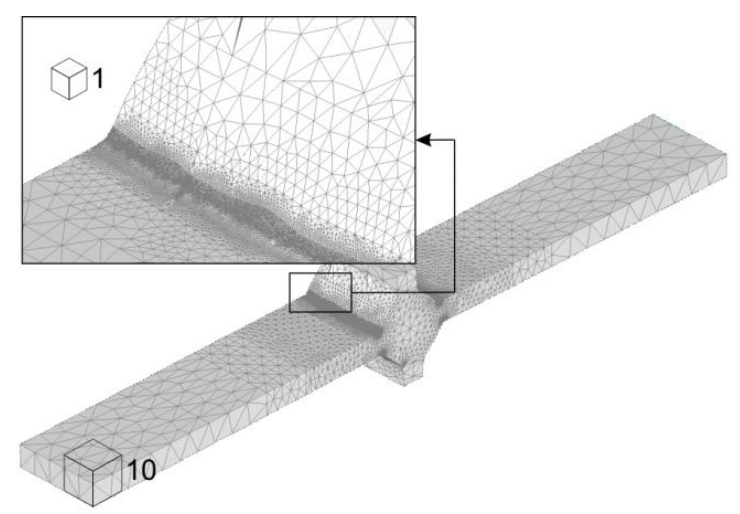

Fig. 4. Mesh density in the specimen model

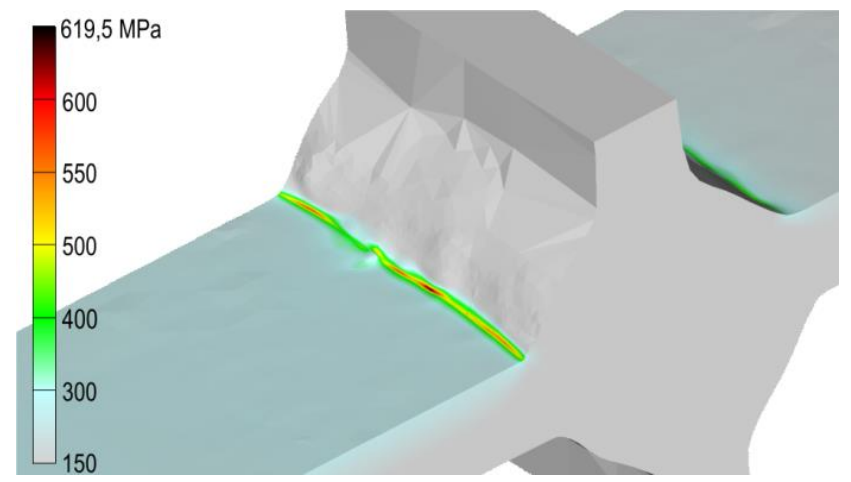

Fig. 5. Maximum principal stress $\sigma_{1}$ (from superposition) distribution in specimen 2.7

Stresses resulting from straightening of the specimen due to jaw gripping do not vary in time. Hence, they can be treated as the mean value of stress courses. On the other hand, the stresses being the result only of the applied nominal stress amplitude $\sigma_{\mathrm{an}}$ (Tab. 1) can be treated as stress amplitudes. Finally, the following maximum normal stresses over each geometry model of specimens were calculated: (a) mean values of normal stress $\sigma_{\mathrm{m}}$ from step (i); (b) amplitudes of normal stresses $\sigma_{\mathrm{a}}$ - from step (ii); (c) superposition of both steps (i)+(ii), i.e. maximum values $\sigma_{\max }$. It must be notice that values of $\sigma_{\max }$ do not have to be sum of $\sigma_{\mathrm{m}}$ and $\sigma_{\mathrm{a}}$ since the normal stresses computed in steps (i) and (ii) could be on different planes and in different points.

Additionaly, the hypothesis of the highly stressed volume proposed by Sosino at all., (1999) was applied to calculate stress denoted as $\sigma_{V 90}$. According this hypothesis, the highly stressed volume is defined as the region where $90 \%$ of the maximum notch stress is exceeded (named as $V_{90}$ ). In this case, value of a $\sigma_{V 90}$ was calculated as a mean stress value from this region. The stresses taken into this calculaion comes from $\sigma_{\max }$ (superposition). The basic material volume $V_{0}$ was defined as a volume under the following condition $\sigma_{\max }(x, y, z) \geq \sigma_{\mathrm{an}}$. All determined and analysed stresses are presented in Tab. 2.

Tab. 2. Values of the analysed stresses

\begin{tabular}{|c|c|c|c|c|}
\hline Specimen & $\sigma_{\mathbf{m}}, \mathbf{M P a}$ & $\sigma_{\mathbf{a}}, \mathbf{M P a}$ & $\begin{array}{c}\sigma_{\mathbf{m a x}}, \\
\mathbf{M P a}\end{array}$ & $\sigma_{\mathbf{V 9 0}}, \mathbf{M P a}$ \\
\hline 1.1 & 147.0 & 562.9 & 591.1 & 265.8 \\
\hline 1.2 & 35.8 & 443.2 & 443.6 & 225.4 \\
\hline 1.4 & 115.2 & 408.1 & 466.1 & 240.5 \\
\hline 1.5 & 127.3 & 415.3 & 481.9 & 254.4 \\
\hline 2.3 & 194.5 & 519.6 & 704.8 & 269.9 \\
\hline 2.5 & 143.7 & 431.1 & 573.4 & 253.3 \\
\hline 2.6 & 141.2 & 448.3 & 589.6 & 245.6 \\
\hline 2.7 & 162.6 & 469.9 & 619.5 & 251.7 \\
\hline 2.8 & 150.4 & 445.4 & 582.9 & 253.6 \\
\hline 2.9 & 41.8 & 393.4 & 410.3 & 217.7 \\
\hline 4.1 & 86.7 & 463.0 & 549.6 & 242.7 \\
\hline 4.5 & 101.8 & 491.4 & 578.6 & 265.6 \\
\hline 4.8 & 147.1 & 409.2 & 515.0 & 254.9 \\
\hline
\end{tabular}

\section{CORRELATION ANALYSIS}

Different stress types: $\sigma_{\mathrm{an}} \cdot \sigma_{\mathrm{a}} \cdot \sigma_{\mathrm{max}} \cdot \sigma_{V 90}$ described in the previous paragraph were used in trials of correlation of the experimental fatigue lives. ASTM procedure (E739-91. 1998) was used to calculate the coefficients of regression line using double logarithmic scales: $\log (N)-\log (\sigma)$. Additionally. sample Pearson linear correlation coefficient $r$ was determined for each applied stress types and fatigue lives:

$r=\frac{\sum_{i=1}^{n}\left(x_{i}-\bar{x}\right)\left(y_{i}-\bar{y}\right)}{\sqrt{\sum_{i=1}^{n}\left(x_{i}-\bar{x}\right)^{2} \sum_{i=1}^{n}\left(y_{i}-\bar{y}\right)^{2}}}$.

where $y_{i}=\log \left(N_{i}\right) \cdot x_{i}=\log \left(\sigma_{i}\right) \cdot \bar{y} \cdot \bar{x}-$ mean values. Also the null hypothesis $H_{0}$ was determined as: there is no correlation between stresses and fatigue lives $(r=0)$ against alternative hypothesis $H_{1}$ that fatigue lives $N$ decrease with stress values increase $(r<0)$. $P$-values using a Student's $t$ distribution for a transformation of the correlation were calculated (MATLAB R2011b). The $p$-values describe the probability of rejection the true hypothesis $H_{0}$ and acceptance of hypothesis $H_{1}$. The lower $p$-value then the correlation more statistically significantly differs from zero. Usually $p$-value lower than 0.05 causes rejection of the null hypothesis. For example Fig. 6 presents regression line with 0.95 probability intervals for nominal stress amplitudes $\sigma_{\text {an }}$ and fatigue lives $N$. The computed correlation coefficient $r$ is small and the more important positive which would means that increasing nominal stress amplitude the fatigue life also increases and this is against our understanding of fatigue mechanism. As a result the $p$-value is very high.

In Figs. 7-9 correlation between fatigue lives and the following stresses $\sigma_{a} . \sigma_{\max } \cdot \sigma_{V 90}$ are presented. respectively. Summarised values of the correlation coefficient $r$. $p$-values and additionally the coefficients of determination $\mathrm{r}^{2}$ are presented in Tab. 3 . The coefficient of determination $\mathrm{r}^{2}$ in \% informs us how many points could be explained by linear relation. For example. in the $\log \left(\sigma_{a}\right)-\log (N)$ relation $17.7 \%$ of fatigue lives $\mathrm{N}$ is explained by linear relation with stress amplitude $\sigma_{\mathrm{a}}$. And. taking into ac- 
count the mean values $\sigma_{\mathrm{m}}$. i.e. influence of initial deformation of specimens improves the correlation and in the $\log \left(\sigma_{\max }\right)-$ $\log (\mathrm{N})$ relation. $23.7 \%$ of fatigue lives $\mathrm{N}$ is explained by linear relation with maximum stresses $\sigma_{\max }$.

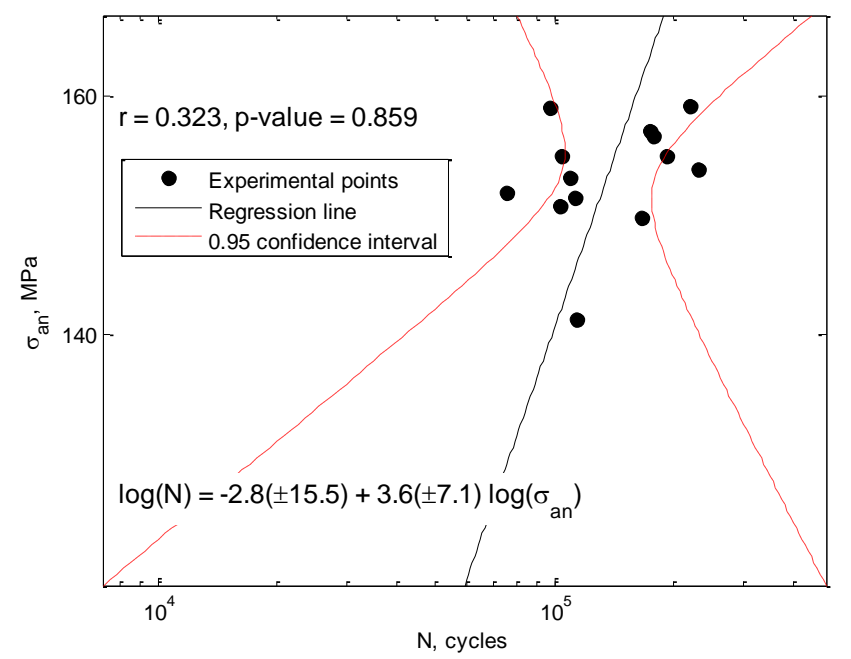

Fig. 6. Correlation between nominal stress amplitudes $\sigma_{\text {an }}$ and fatigue lives $N$

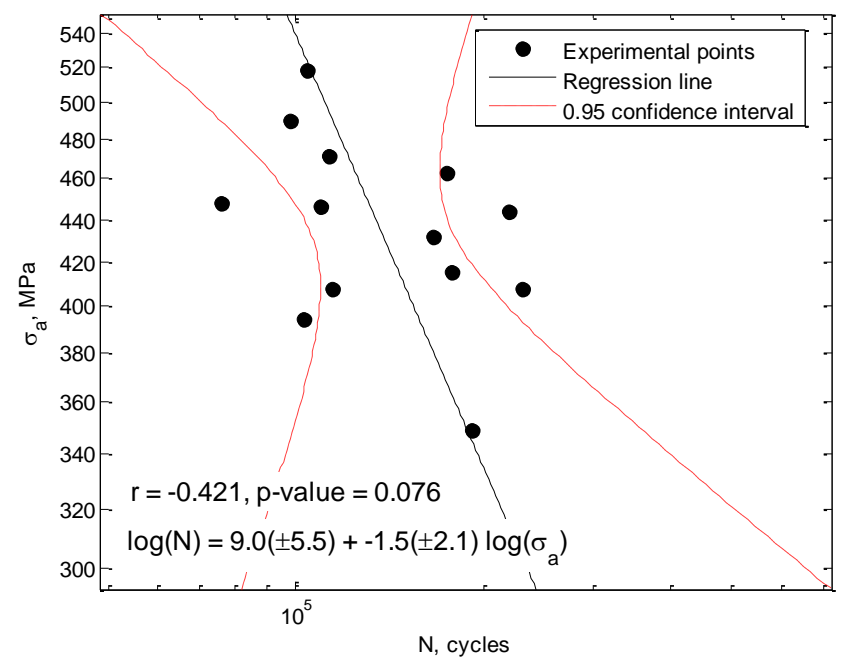

Fig. 7. Correlation between stress amplitudes $\sigma_{\mathrm{a}}$ and fatigue lives $N$

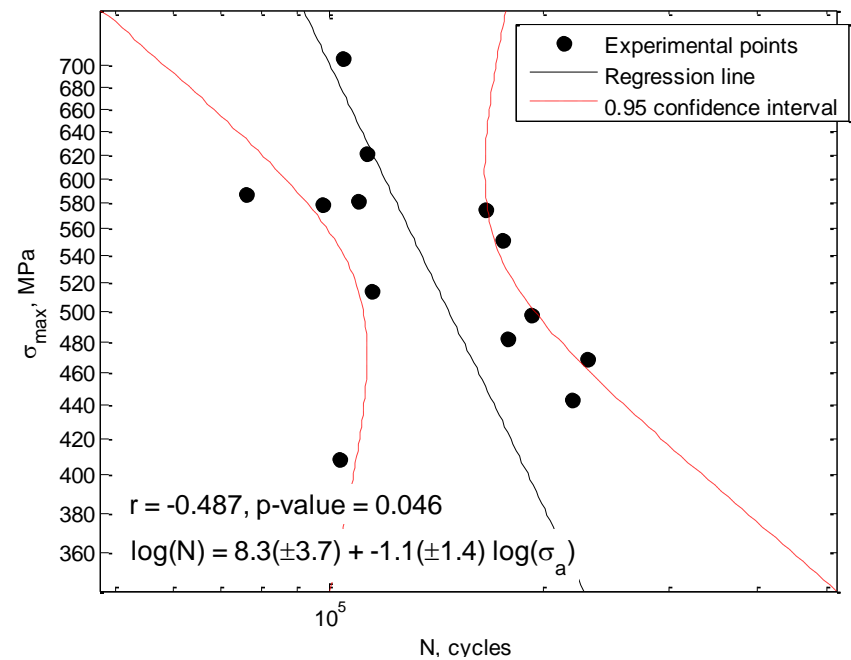

Fig. 8. Correlation between stresses $\sigma_{\max }$ and fatigue lives $N$

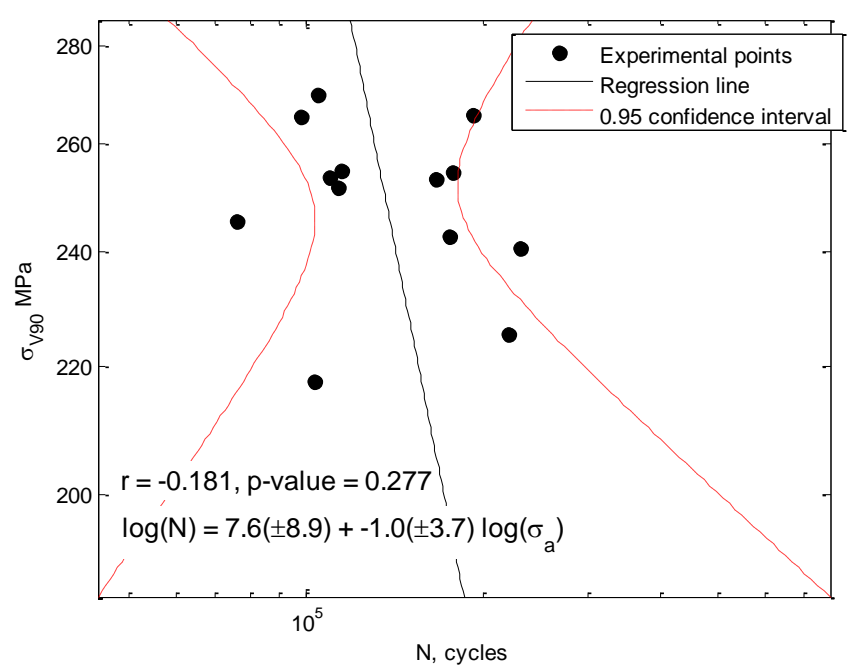

Fig. 9. Correlation between $\sigma_{V 90}$ stresses and fatigue lives $N$

Tab. 3. Values of Pearson's correlation coefficient. $p$-values and coefficient of determination

\begin{tabular}{|c|c|c|c|}
\hline Case (log scales) & $\boldsymbol{r}$ & $\boldsymbol{p}$-value & $\boldsymbol{r}^{\mathbf{2}} \mathbf{\%}$ \\
\hline$\sigma_{a n}$ vs. $N_{\text {exp }}$ & 0.323 & 0.859 & 10.4 \\
\hline$\sigma_{a}$ vs. $N_{\text {exp }}$ & -0.421 & 0.076 & 17.7 \\
\hline$\sigma_{\max }$ vs. $N_{\text {exp }}$ & $-\mathbf{0 . 4 8 7}$ & $\mathbf{0 . 0 4 6}$ & $\mathbf{2 3 . 7}$ \\
\hline$\sigma_{V 90}$ vs. $N_{\text {exp }}$ & -0.181 & 0.277 & 3.3 \\
\hline
\end{tabular}

Taking into account simple non-local method. i.e. highly stress volume approach in which averaged stress over the volume of with $10 \%$ of the highest stresses is computed did not result in sufficient correlation.

\section{SUMMARY}

- There is no correlation between nominal stress amplitudes $(153.1 \pm 5.9 \mathrm{MPa})$ and fatigue lives.

- Application of maximum normal stress amplitudes values $\sigma_{\mathrm{a}}$ over the whole specimen volume $\mathrm{V}$ improves the correlation with fatigue lives $\mathrm{N}$.

- The best and statistically significant correlation was obtained between maximum values of normal stresses $\sigma_{\max }$ and fatigue lives $\mathrm{N}$. The hypothesis of non-correlation in this case is rejected at significance level $\alpha=0.05$.

- The correlation of fatigue lives and averaged values of normal stresses over the $10 \%$ of the highest stresses is very weak $r=-0.181$.

- Finally. it can be stated that local maximum values of stresses influence the fatigue life of non-load carrying cruciform steel weld joints by around $23.7 \%$. However. for more reliable analysis the number of specimens must be increased.

\section{REFERENCES}

1. Alam M.M.. Barsoum Z.. Jonsén P.. Kaplan A.F.H.. Häggblad H.A (2010). The influence of surface geometry and topography on the fatigue cracking behaviour of laser hybrid welded eccentric fillet joints. Applied Surface Science. 256. 1936-1945. 
2. ASTM E739-91(1998). Standard Practice for Statistical Analysis of Linear or Linearized Stress-Life (S-N) and Strain-Life $(\varepsilon-N)$ Fatigue Data. ASTM Int West Conshohocken PA 1998;03.01.

3. Barsoum Z.. Gustafsson M. (2009). Fatigue of high strength steel joints welded with low temperature transformation consumables. Engineering Failure Analysis. 16. 2186-2194.

4. Barsoum Z.. Jonsson B. (2011). Influence of weld quality on the fatigue strength in seam welds. Engineering Failure Analysis. 18. 971-979.

5. Blacha Ł.. Karolczuk A.. Bański R.. Stasiuk P. (2013). Application of the weakest link analysis to the area of fatigue design of steel welded joints. Engineering Failure Analysis. 35. 665-677.

6. Blacha Ł.. Karolczuk A.. Lagoda T. (2011). Modeling of stress in welded joints under consideration of plastic strains in fatigue life calculations. Materials Testing. 53. 339-343.

7. Hou C-Y. (2007). Fatigue analysis of welded joints with the aid of real three-dimensional weld toe geometry. International Journal of Fatigue. 29. 772-785.

8. Kaffenberger M.. Malikoutsakis M.. Savaidis G.. Vormwald M. (2012). Fatigue resistance of weld ends. Computational Materials Science. 52. 287-292.
9. Kirkhope K.J.. Bell R.. Caron L.. Basu R.I.. Ma K.-T. (1999). Weld detail fatigue life improvement techniques. Part 1: review. Marine Structures. 12. 447-474.

10. Lee C-H.. Chang K-H.. Jang G-C.. Lee C-Y. (2009). Effect of weld geometry on the fatigue life of non-load-carrying fillet welded cruciform joints. Engineering Failure Analysis. 16. 849-855.

11. MATLAB R2011b (2011). Statistics toolbox. version 7.6.

12. Nykänen T.. Marquis G.. Björk T. (2007) Fatigue analysis of nonload-carrying fillet welded cruciform joints. Engineering Fracture Mechanics. 74. 399-415.

13. Sonsino C.M.. Radaj D.. Brandt U.. Lehrke H.P. (1999) Fatigue assessment of welded joints in AlMg 4.5Mn aluminium alloy (AA 5083 ) by local approaches. International Journal of Fatigue. 21. 985-999.

14. Ting W.. Dongpo W.. Lixing H.. Yufeng Z. (2009) Discussion on fatigue design of welded joints enhanced by ultrasonic peening treatment (UPT). International Journal of Fatigue. 31. 644-650.

15. Williams H.E.. Ottsen H.. Lawrence F.V.. Munse W.H. (1970) The effects of weld geometry on the fatigue behavior of welded connections. Civil Engineering Studies. University of Illinois Urbana. Illinois. Structural Research Series No.366. 